\title{
Fusiform gold nanoparticles by pulsed plasma in liquid method
}

\author{
Saadat Sulaimankulova ${ }^{1} \cdot$ Altynai Mametova ${ }^{2} \cdot$ Zhypargul Abdullaeva $^{2}$ (1)
}

(c) Springer Nature Switzerland AG 2019

\begin{abstract}
We have synthesized fusiform gold nanoparticles by recovering gold from a solution of gold nanoparticles obtained by dispersing of gold electrodes in hexane by pulsed plasm in liquid method. Formation of fusiform gold nanoparticles with length from 50 to $150 \mathrm{~nm}$, and diameter of 5-15 nm was achieved by pulsed plasma in liquid method. Fusiform gold nanoparticles obtained by our method are different from the spindle-shaped gold nanoparticles which were synthesized from the growth solution, due to their loose structure, while spindle-shaped gold nanoparticles are dense and much larger in size (length 300-400 nm, diameter 100-150 nm). In addition to this work, dumbbell-shaped magnetite/gold $\left(\mathrm{Fe}_{3} \mathrm{O}_{4} /\right.$ $\mathrm{Au})$ nanoparticles were synthesized by using magnetite nanoparticles obtained in a cetylpyridinium bromide $(\mathrm{CpyBr})$ solution with concentration of $0.1 \%$ and a gold nanosolution, where $0.1 \%$ sodium citrate solution was applied as a reducing agent. Our proposed method is characterized by the forming of discharge localization during the electrodes erosion process, simpler and does not require use of nuclei in the form of spherical gold nanoparticles and presence of growth solution. Fusiform gold nanoparticles were formed by simple reduction with sodium citrate from gold nano-solution.
\end{abstract}

Keywords Fusiform · Gold nanoparticles · Magnetite · Synthesis · Pulsed plasma · Nano-solution

\section{Introduction}

Gold nanoparticles have been attracting big attention due to their extensive application in many fields such as chemistry, physics, material science, electronics, catalysis and bionanotechnology [32]. Medical applications of gold nanoparticles have been tested in biomedicine [20] and surgery [18], in vitro biosensing, in vivo imaging, drug delivery, and tissue engineering [1, 24], therapy and imaging [3]. Other applications of gold nanoparticles are including sensing [11] and antibacterial [34] were also reported recently.

Various methods such as green synthesis oxidation [2, $9,19,27,43]$, chemical reduction $[17,23,50]$, bacterial synthesis $[4,7,35]$, fungal synthesis [42], laser ablation $[8,16$,
48], CVD method [25, 31, 40, 41, 46], solvothermal [6, 14], halogen-free synthesis $[22,44]$ and seed-mediated synthesis $[26,36]$ have been used for the synthesis of gold nanoparticles with different size, shapes and properties depending on the synthesis method and experimental conditions, as shown in the Table 1.

Gold nanoparticles (AuNPs) were synthesized at room temperature by a simple, rapid, and green route using fresh squeezed apple juice as a reducing reagent, where morphology of obtained AuNPs was based on the particle color, stability, and color change suitable for colorimetric detection of cysteine (Cys), are synthesized using $5 \mathrm{~mL}$ of $10 \%$ apple juice, $1 \mathrm{~mL}$ of $10 \mathrm{mM}$ gold precursor solution, and $1 \mathrm{~mL}$ of $0.1 \mathrm{M} \mathrm{NaOH}[10]$.

Electronic supplementary material The online version of this article (https://doi.org/10.1007/s42452-019-1345-z) contains supplementary material, which is available to authorized users.

Zhypargul Abdullaeva, jypargul@gmail.com | ${ }^{1}$ Nanotechnology Laboratory, National Academy of Sciences of the Kyrgyz Republic, Chui 256, 720000 Bishkek, Kyrgyzstan. ${ }^{2}$ Department of Clinical Biochemistry and Pathophysiology, Medical Faculty, Osh State University, Jolon Mamytov Campus, 723500 Osh, Kyrgyzstan.

SN Applied Sciences (2019) 1:1427 | https://doi.org/10.1007/s42452-019-1345-z

Received: 3 May 2019 / Accepted: 24 September 2019 / Published online: 16 October 2019 
Table 1 Various methods used for synthesis of gold nanoparticles with various size

\begin{tabular}{lll}
\hline Preparation method & Au NP size (nm) & References \\
\hline Green synthesis oxidation & 15 & Kunoh et al. [8] \\
Chemical reduction & $1-3.5$ & Yeh et al. [9] \\
Bacterial (R. capsulata) & $50-400$ & Abdullaeva [10] \\
Laser ablation & 7 & Amendola et al. [11] \\
CVD method & $5-100$ & Takagi et al. [12] \\
Solvothermal method & $7-15$ & Ahmad et al. [13] \\
Halogen-free synthesis & $<10$ & Sashuk et al. [14] \\
Seed-mediated synthesis & $18-100$ & Kumar et al. [15] \\
\hline
\end{tabular}

Anisotropic gold nanoparticles (GNPs) and nanostructures have been produced [49]; including triangles, stars and rods which are represented in the Fig. 1 below. Gold nanoparticles with fusiform shape have been recently fabricated by controlling the volume of the growth solution with shape evolutions ranging from fusiform nanoparticles to 1-D rods [13]. The term fusiform can be referred to a spindle-shaped form of nanostructures with wide area in the center. Previously spindle-shaped gold nanoparticles were successfully prepared in large amount by using a simple wet chemical approach method, where L-ascorbic acid (AA) used as reductant in the presence of cetyltrimethylammonium bromide (CTAB) at room temperature [29].

In this article we are reporting the synthesis of fusiform gold nanoparticles by using the impulse plasma in a liquid method, used for the synthesis of metal oxide, carbon and carbon coated metal nanoparticles [5, 37, 38]. Pulsed plasma in a liquid method is based on a dispersion phenomenon of interfacing metal electrodes under vibration. Characteristic of this discharge form is the localization of the erosion process. A single pulse has an extremely short duration $\left(10^{-3}-10^{-5} \mathrm{~s}\right)$, a high current density $\left(10^{6}-10^{8} \mathrm{~A} / \mathrm{cm}^{2}\right)$ in the impact zone, and very high temperature in the discharge channel $\left(10^{4}-10^{5} \mathrm{~K}\right)$ and a pressure of $3^{-10} \mathrm{kbar}$. Drawback of this method is sometimes appearing in separation of synthesized nanoparticles, due to various phases and morphology of nanoparticles.

Gold nanoparticles prepared by modified citrate reduction method under sonication exhibited uniform spherical shapes, which was shown by ultraviolet (UV)-Visible absorption spectrum of the two final products represented in the Fig. 2, because the absorption peak was centered between 520 and $540 \mathrm{~nm}[28]$.

\section{Experimental method}

For the synthesis of fusiform gold nanoparticles, we have applied pulsed plasma which was generated between two gold metal rod shaped electrodes submerged in hexane

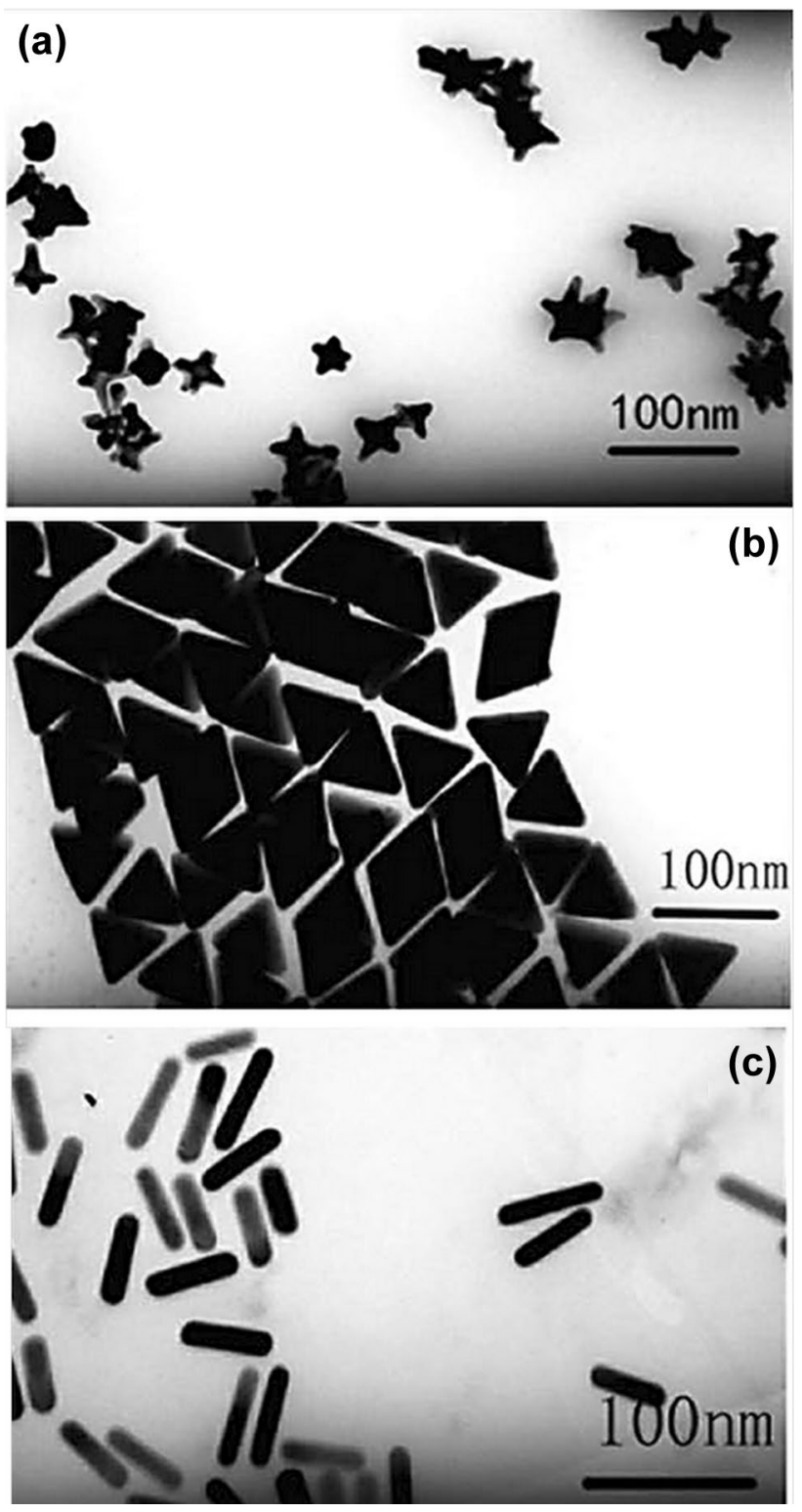

Fig. 1 Anisotropic gold nanoparticles with different shapes in the form of stars, triangles and rods. Reproduced with permission from Xie et al. [49]

solution. Energy of the simple impulse was appeid with electrical energy of $0.05 \mathrm{~J}$, capacity of the condensator was $4 \mu \mathrm{Fs}$ (microfarads). Schematic of the experimental setup was shown in the Fig. 3. During the pulsed plasma in liquid physical effects caused by electrical field can be explained by the Cauchy's equation of motion and continuity [30]:

$\rho \frac{D v}{D t}=\rho f-\nabla P+\tau$

$\frac{\partial \rho}{\partial t}=\nabla \cdot(\rho v)$

\section{SN Applied Sciences}




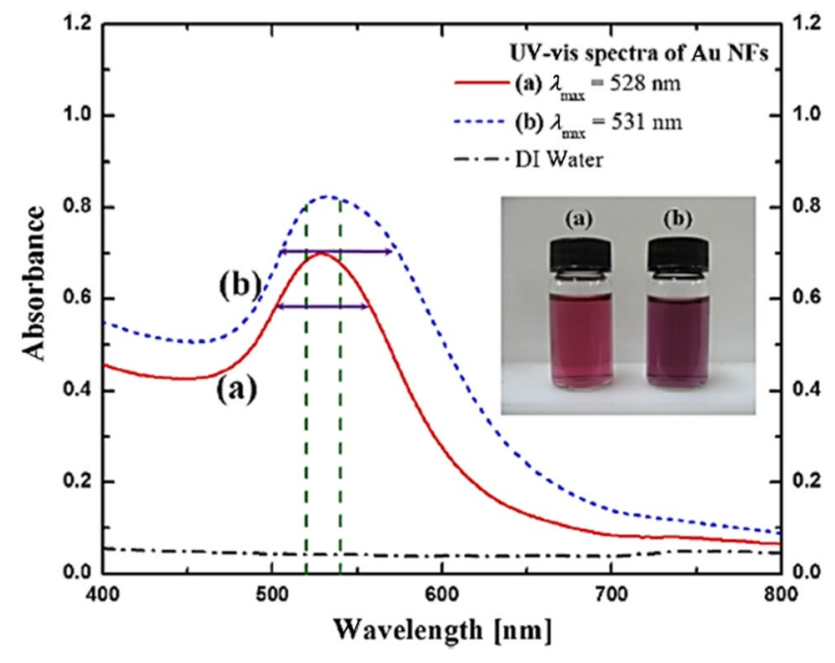

Fig. 2 UV-Visible spectroscopy of synthesized gold suspensions. (a) Gold suspension (maximum absorption peak $\lambda_{\max }$ is $528 \mathrm{~nm}$ ) prepared with $243 \mathrm{~kJ}$ (30 min with $135 \mathrm{~W}$ ultrasonic power) of sonication; (b) gold suspension (maximum absorption peak $\lambda_{\max }$ is $531 \mathrm{~nm}$ ) prepared with $729 \mathrm{~kJ}$ ( 90 min with $135 \mathrm{~W}$ ultrasonic power) of sonication. Reproduced from Lee et al. [22] under permission license CC-BY2.0

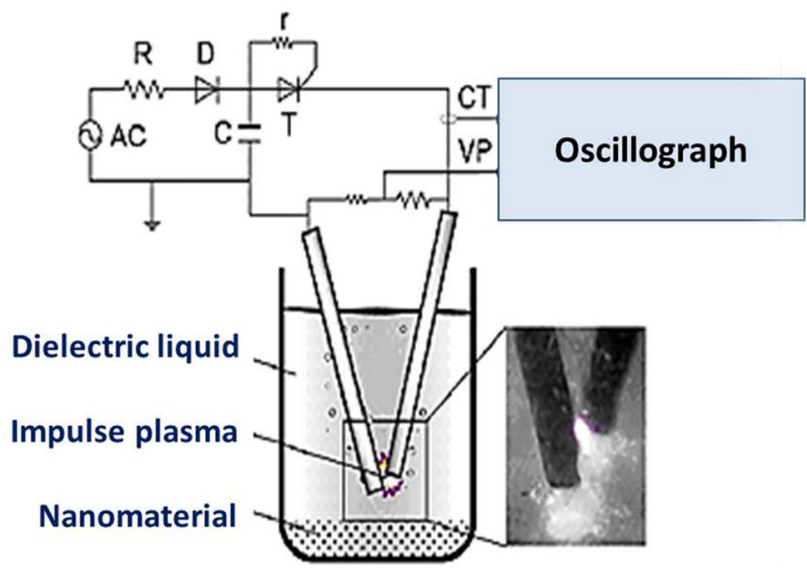

Fig. 3 Schematic of the experimental setup for synthesis of fusiform gold nanoparticles by pulsed plasma in liquid method

here, Eq. (1) is the motion, and Eq. (2) is the continuity equations respectively; where, $v$, and mass density, $\rho$, in a fluid as functions of the pressure $-\mathrm{P}$, body forces $-f$, and viscous stress- $\tau$.

Pulsed plasma processes in the presence of organic liquids such as hexane may cause the introduction of reactive species (e.g., $\mathrm{OH}$ - and $\mathrm{H}$ - radicals) into organic compounds through spatial and temporal control of the plasma discharge [47]. Recently, in-liquid plasma methods can be broadly classified into four categories, depending on the electrode configurations and energy sources, such as: (1) Plasma A: direct discharge between two electrodes using an AC (plus) power supply; (2) Plasma B: contact discharge between an electrode and the surface of the surrounding electrolyte using a DC power supply; (3) Plasma C: plasma generated with either radio frequency (RF) or microwave (MW) irradiation; (4) Plasma D: plasma generated using the laser ablation technique [21].

In our case, a single impulse discharge was generated between two gold electrodes immersed in a liquid medium (hexane). Pulsed plasma in dielectric liquid resulted from the breakdown of the inter-electrode space with a high potential difference between the electrodes and a relatively small source power, which is insufficient to initiate an arc discharge.

The energy of a single pulse $(0.05 \mathrm{~J})$ was regulated by changing the power of capacitors $C$ in an electrical circuit. The energy value was selected as a result of numerous experiments conducted by the authors of this work in collaboration with colleagues for many years. Selected energy of a single pulse is sufficient to disperse any even the most refractory conductive material with the formation of nanostructures [45]. During synthesis of fusiform gold nanoparticles electrodes of pure gold (99.99\%) were adjusted inside hexane solution and pulsed discharge was applied. Obtained gold nanoparticles were placed in a conical flask and exposed to aqua regia for $20 \mathrm{~min}$. As a result, a $1 \%$ gold-yellow-orange solution was obtained. After that, $1 \mathrm{ml}$ of $1 \%$ sodium citrate solution was added to $1 \mathrm{ml}$ of the resulting solution. Discoloration of the initial solution was observed. Precipitate was centrifuged at $2000 \mathrm{rpm}$ for $30 \mathrm{~min}$, and then separated from the medium by decantation and filtration. Dried powders were subjected to physicochemical analyses.

\subsection{Reagents and materials}

Gold metal rod electrodes with purity of $99.99 \%$, diameter of $2 \mathrm{~mm}$ and length of 10-15 mm were used. Hydrochloric acid $(\mathrm{HCl})$ with purity of $99.9 \%$ and nitric acid $\left(\mathrm{HNO}_{3}\right)$ with concentration of $58.9 \%$, hexane solution with concengtration of $97 \%$, sodium citrate in water solution of $5.5 \%$ were used for experiments.

\subsection{Characterization of gold NPs}

X-ray diffraction (XRD) measurement was performed on a Rigaku RINT-2500HV diffractometer with Cu-Ka radiation wavelength of $0.15406 \mathrm{~nm}$. Tube voltage was applied as $40 \mathrm{kV}$, and the current was $200 \mathrm{~mA}$. XRD patterns were taken in the range of $(2 \theta) 20^{\circ}-80^{\circ}$. Transmission electron 
microscopy (TEM) images of as synthesized fusiform gold nanoparticles were taken using a JEOL 1400 microscope with Specification of maximum accelerating voltage $120 \mathrm{kV}$, maximum resolution of $0.2 \mathrm{~nm}$ installed in the Nanobiomedcenter of the Adam Mickiewicz University, Poznań, Poland.

\section{Results and discussions}

\subsection{Transmission electron microscopy analyses}

Transmission electron microscopy (TEM) analysis of resulting fusiform gold nanoparticles was carried out by dropping fusiform gold nanoparticles solution on the copper grid and adjusting the sample holder into the TEM microscope. TEM image of the sample clearly shows TEM images of fusiform gold nanoparticles synthesized by pulsed plasma in a liquid method: $(a, d)$ rough and soft fusiform gold nanoparticles; $(b, c)$ aggregates of fusiform gold nanoparticles in
Fig. 4. Fusiform gold nanoparticles have a length of from 50 to $150 \mathrm{~nm}$ and diameter of 5 to $15 \mathrm{~nm}$. The fusiform gold nanoparticles obtained by pulsed plasma in liquid method are different from the spindle-shaped nanoparticles synthesized by the growth solution [18]: our nanoparticles are loose, while those obtained in a growth solution are dense and much larger in size (length 300-400 nm, diameter $\sim 100-150 \mathrm{~nm}$ ). Our proposed method is simpler and does not require the use of germs in the form of spherical gold nanoparticles and growth solution. Fusiform gold nanoparticles formed by simple reduction with sodium citrate from gold nano-solution.

\subsection{X-ray diffraction analysis}

XRD characterization of fusiform gold nanoparticles was taken from dried powder samples revealed that the gold nanoparticles synthesized by pulsed plasma in a liquid method existing predominantly in a face-centered-cubic (FCC) phase, with cell parameters of $a=0.4078 \mathrm{~nm}$ and
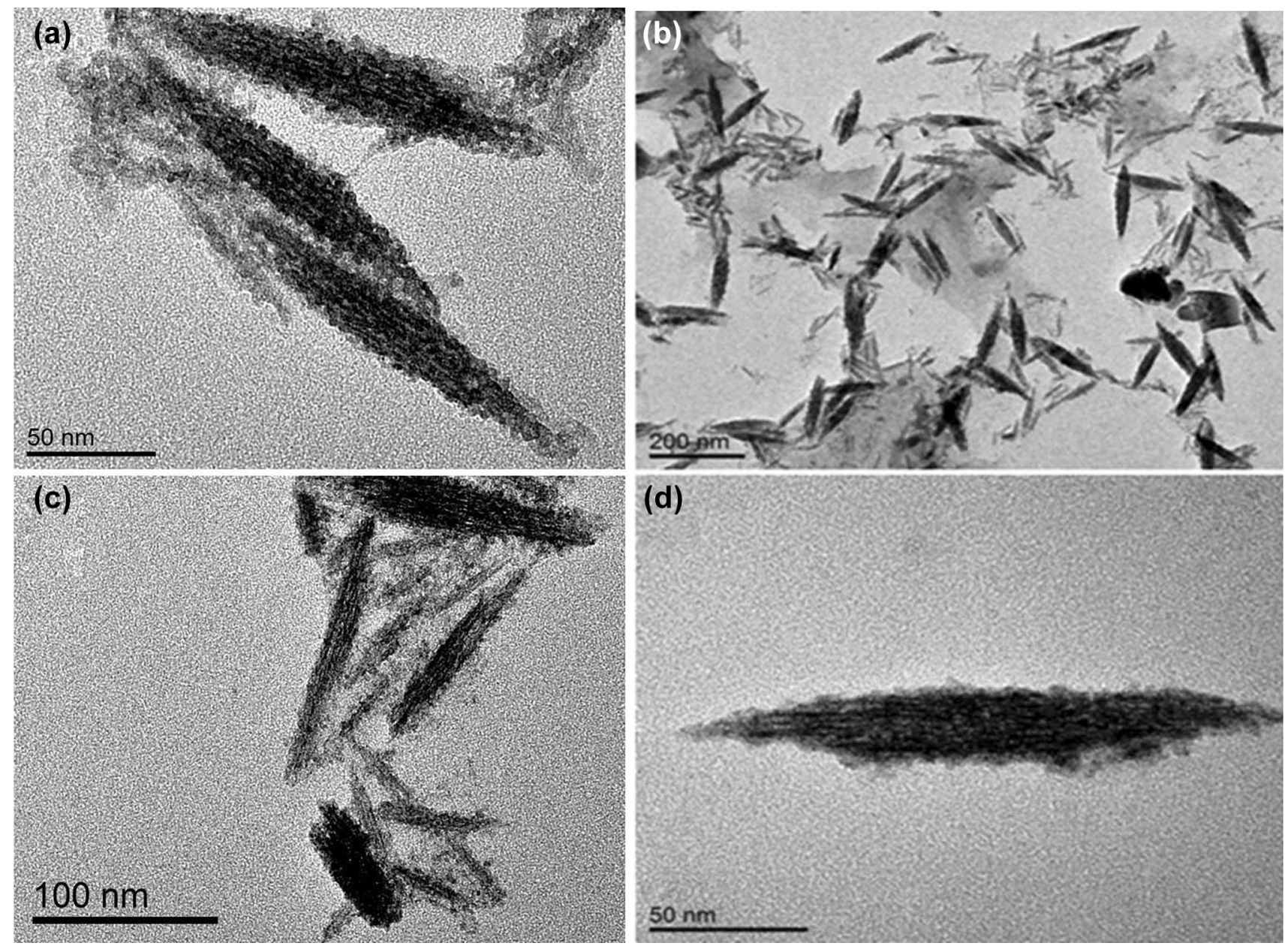

Fig. 4 TEM images of fusiform gold nanoparticles synthesized by pulsed plasma in a liquid method: $\mathbf{a}, \mathbf{d}$ rough and soft fusiform gold nanoparticles; $\mathbf{b}, \mathbf{c}$ aggregates of fusiform gold nanoparticles 


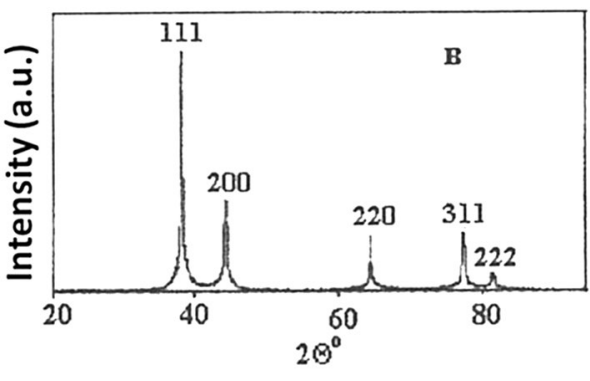

Fig. 5 XRD pattern of fusiform gold nanoparticles synthesized by pulsed plasma in a liquid method

average size of gold nanoparticles equal to $2.5 \mathrm{~nm}$. As it is shown in the Fig. 5, presence of intense peaks corresponding to $2 \theta$ values of (111), (200), (220), (311) and (222) in the powder $\mathrm{X}$-ray diffraction pattern agrees with those values reported in literature (JCPDS No. 04-0784), as well as previously reported spindle shaped gold nanoparticles [12].

Supplementary Table 2 is showing interplanar $d$ spacing for fusiform gold nanoparticles which were calculated by using the following equation:

$\frac{1}{d^{2}}=\frac{h^{2}+k^{2}+l^{2}}{a^{2}}$

According to these calculations the interplanar $d$ spacings for fusiform gold nanoparticles were as 2.36182 for (111), 2.04570 for (200), 1.44497 for (220) and 1.23268 for (311), respectively.

In addition to this work, we have synthesized $\mathrm{Fe}_{3} \mathrm{O}_{4} / \mathrm{Au}$ nanoparticles by using magnetite [33] nanoparticles which were obtained in a cetylpyridinium bromide solution of $0.1 \% \mathrm{CPyBr}$ and a gold nanosolution. Here $0.1 \%$ sodium citrate solution was applied as a reducing agent [51]. Figure 6 shows TEM image of samples obtained by treating $0.1 \mathrm{~g}$ of magnetite nanoparticles with a solution of sodium citrate, then with a gold nanosolution. Here adsorption of cationic $\mathrm{CPyBr}$ on the surface of freshly formed magnetite nanoparticles was carried out in order to stabilize them, prevent oxidation and transition to $\mathrm{Fe}_{2} \mathrm{O}_{3}$ due to hydrophobization of the nanoparticles surface. Dumbbellshaped $\mathrm{Fe}_{3} \mathrm{O}_{4} / \mathrm{Au}$ nanoparticles were found as shown by arrows in the Fig. 6a, b.

Biomedical applications of such spindle shaped gold nanoparticles have been previously reported [39]. Cetrimonium bromide $\left[\left(\mathrm{C}_{16} \mathrm{H}_{33}\right) \mathrm{N}\left(\mathrm{CH}_{3}\right)_{3}\right] \mathrm{Br}$ (CTAB) forms rod-like micelles in the solution above its critical micelle concentration and form bilayers on the surface of gold nanorods, which is resulting in a stable dispersion of gold nanorods. Nanorods then capped with a bilayer of surfactant $C T A B$ have positive charge. However, $C T A B$ is known for its cytotoxicity [15]; hence, it is necessary to mask the CTAB layer for biomedical applications. The CTAB-coated gold nanorods were further covered with poly(sodium 4-styrenesulfonate (PSS) by electrostatic interactions to obtain the negatively charged gold nanorods. $\zeta$-potential analysis of gold nanorods was performed before and after PSS coating. CTABstabilized gold nanorods showed a positive charge on the surface due to the presence of quaternary amine hydrophilic head groups from adsorbed CTAB, whereas PSS-capped gold nanorods showed a negative charge on the surface due to the presence of anionic $-\mathrm{SO}_{3}$ groups. Thus, $\zeta$-potential analysis confirmed successful coating of PSS on the surface of CTAB-capped gold nanorods. This surface modification of gold nanorods was found to be very effective in reducing the cytotoxicity of gold nanorods caused by an excess of CTAB and formed a stable dispersion of gold nanorods for further attachment of biomolecules. The bioconjugation of gold nanorods and the detection of IgG are represented schematically
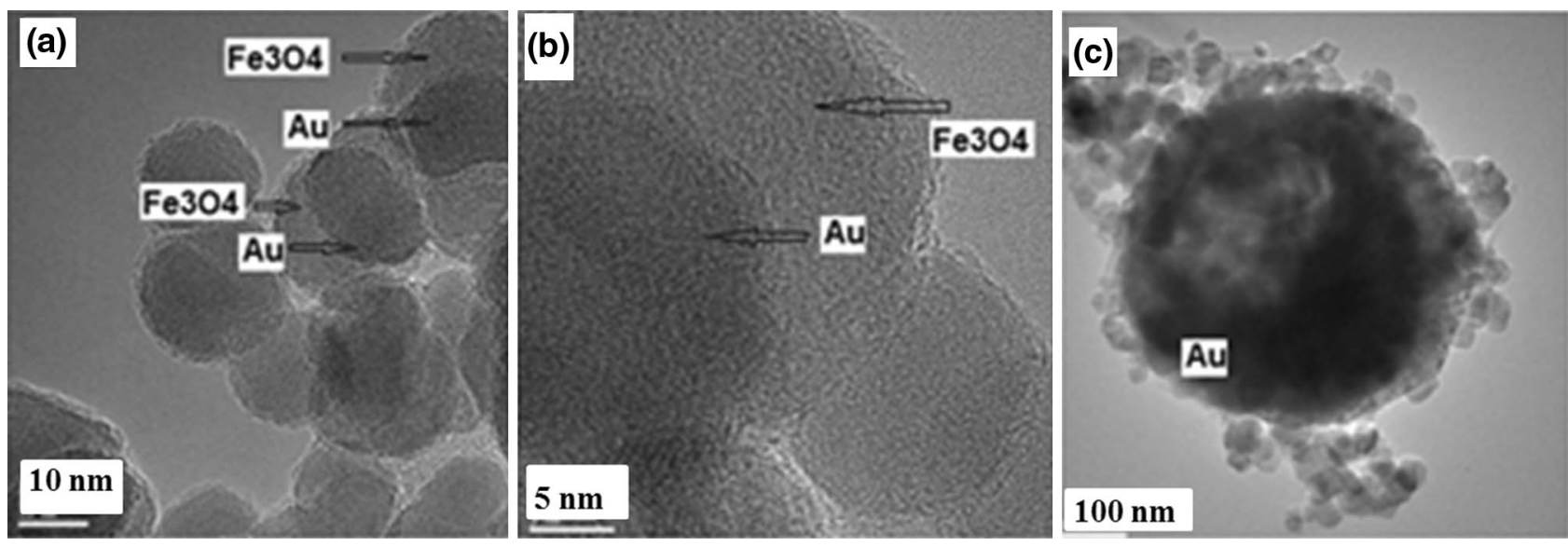

Fig. 6 Dumbbell-shaped $\mathrm{Fe}_{3} \mathrm{O}_{4} / \mathrm{Au}$ nanoparticles obtained from magnetite using the pulsed plasma in liquid 
Fig. 7 Schematic representation of bioconjugation of gold nanorods and the detection of g-lgG through the aggregation of gold nanorods. Reproduced with permission from Parab et al. [39] Copyright (2009) American Chemical Society)
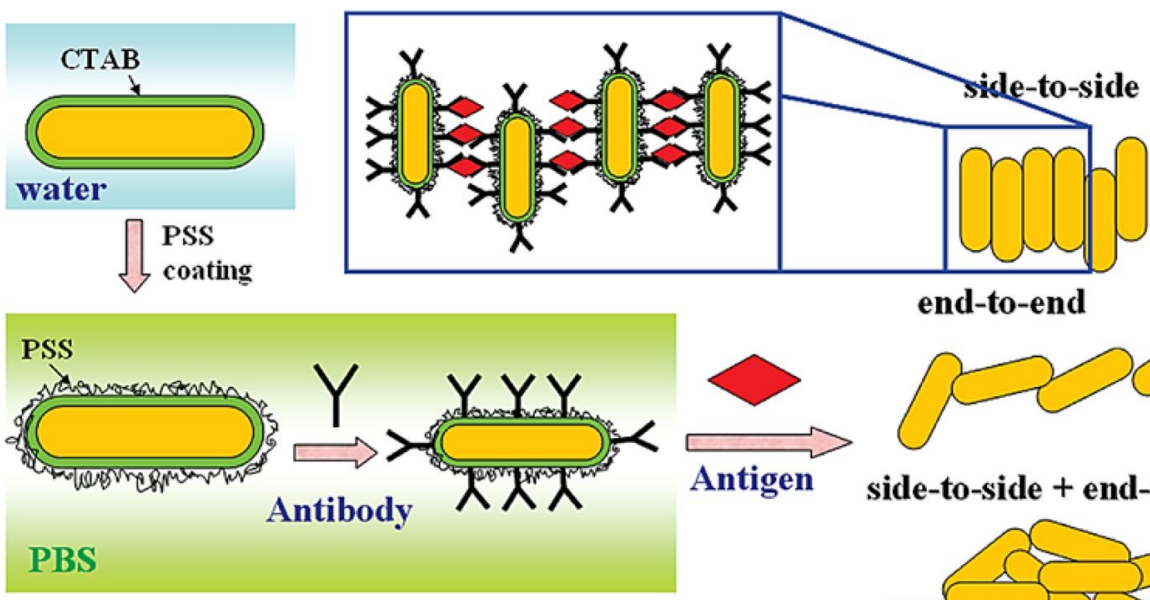

in Fig. 7 (reproduced with permission from Parab et al. [39] Copyright (2009) American Chemical Society).

\section{Conclusions}

Fusiform gold nanoparticles were successfully synthesized by using the pulsed plasm in a liquid method. Pulsed plasma in dielectric liquid resulted from the breakdown of the inter-electrode space with a high potential difference between the electrodes and a relatively small source power, which is insufficient to initiate an arc discharge. A single pulse has an extremely short duration $\left(10^{-3}-10^{-5} \mathrm{~s}\right)$, a high current density $\left(10^{6}-10^{8} \mathrm{~A} / \mathrm{cm}^{2}\right)$, a very high temperature in the discharge channel $\left(10^{4}-10^{5} \mathrm{~K}\right)$, and a pressure of $3^{-10} \mathrm{kbar}$ and spreads in the amount of $10^{-3}-10^{-4} \mathrm{~cm}^{3}$, i.e. characterized by strong localization effects on the solid. TEM observations of as-synthesized sample clearly showed formation of fusiform gold nanoparticles with a length of 50 to $150 \mathrm{~nm}$ and diameter of 5 to $15 \mathrm{~nm}$. As properties, morphology and synthesis of fusiform gold nanoparticles were not researched well enough, our work is original and valuable contribution to the synthesis of fusiform gold nanoparticles.

Acknowledgements Authors are thankful to the Adam Mickiewicz University for TEM analyses of fusiform gold nanoparticles. This research was supported by funding from TOSCA II Post-doc Scholarships, from 19/09/2013 to 31/06/2014, Nanobiomedcenter of the Adam Mickiewicz University, Poznań, Poland.

\section{Compliance with ethical standards}

Conflict of interest The authors declare that they have no conflict of interest.

\section{References}

1. Abdelhalim MAK, Mady MM, Ghannam MM (2011) Rheological and dielectric properties of different gold nanoparticle sizes. Lipids Health Dis 10:208. https://doi. org/10.1186/1476-511X-10-208

2. Abdel-Raouf N, Al-Enazi NM, Ibraheem IBM (2017) Green biosynthesis of gold nanoparticles using Galaxaura elongata and characterization of their antibacterial activity. Arab J Chem 10(2):S3029-S3039. https://doi.org/10.1016/j.arabjc.2013.11.044

3. Abdullaeva $Z$ (2017), Nanomaterials in daily life. Springer International Publishing. ISBN 978-3-319-57215-4, https://doi. org/10.1007/978-3-319-57216-1

4. Abdullaeva Z (2017) Synthesis of nanoparticles and nanomaterials: biological approaches. Springer International Publishing AG. ISBN 9783319540740, https://doi.org/10.1007/978-3-319-54075 $-7$

5. Abdullaeva Z, Omurzak E, Iwamoto C, Ganapathy HS, Sulaimankulova S, Liliang C, Mashimo T (2012) Onion-like carbon-encapsulated $\mathrm{Co}, \mathrm{Ni}$, and Fe magnetic nanoparticles with low cytotoxicity synthesized by a pulsed plasma in a liquid. Carbon 50(5):1776-1785. https://doi.org/10.1016/j.carbo n.2011.12.025

6. Ahmad T, Wani IA, Lone IH, Ganguly A, Manzoor N, Ahmad A, Ahmed J, Al-Shihri AS (2013) Antifungal activity of gold nanoparticles prepared by solvothermal method. Mater Res Bull 48(1):12-20. https://doi.org/10.1016/j.materresbull.2012.09.069

7. Ali J, Ali N, Wang L, Waseem H, Pan G (2019) Revisiting the mechanistic pathways for bacterial mediated synthesis of noble metal nanoparticles. J Microbiol Methods 159:18-25. https:// doi.org/10.1016/j.mimet.2019.02.010

8. Amendola V, Rizzi GA, Polizzi S, Meneghetti M (2005) Synthesis of gold nanoparticles by laser ablation in toluene: quenching and recovery of the surface plasmon absorption. J Phys Chem B 109(49):23125-23128. https://doi.org/10.1021/jp055783v

9. Ankamwar B, Damle C, Ahmad A, Sastry M (2005) Biosynthesis of gold and silver nanoparticles using Emblica Officinalis fruit extract, their phase transfer and transmetallation in an organic solution. J Nanosci Nanotechnol 5(10):1665-1671. https://doi. org/10.1166/jnn.2005.184

10. Bagci PO, Wang Y, Gunasekaran S (2015) A simple and green route for room temperature synthesis of gold nanoparticles 
and selective colorimetric detection of cysteine. J Food Sci 80:N2071-N2078. https://doi.org/10.1111/1750-3841.12974

11. Bindhu MR, Umadevi M (2014) Silver and gold nanoparticles for sensor and antibacterial applications. Spectrochimica Acta Part A Mol Biomol Spectrosc 128:37-45. https://doi.org/10.1016/j. saa.2014.02.119

12. Chen R, Wu J, Li H, Cheng G, Lu Z, Che CM (2010) Fabrication of gold nanoparticles with different morphologies in HEPES buffer. Rare Met 29:180. https://doi.org/10.1007/s12598-010-0031-5

13. Chen HM, Peng H-C, Liu R-S, Asakura K, Lee C-L, Lee J-F, Hu S-F (2005) Controlling the length and shape of gold nanorods. J Phys Chem B 109(42):19553-19555. https://doi.org/10.1021/ jp053657l

14. Choi J, Park S, Stojanović Z, Han HS, Lee J, Seok HK et al (2013) Facile solvothermal preparation of monodisperse gold nanoparticles and their engineered assembly of ferritin-gold nanoclusters. Langmuir 29(50):15698-15703. https://doi.org/10.1021/ la403888f

15. Connor EE, Mwamuka J, Gole A, Murphy CJ, Wyatt MD (2005) Gold nanoparticles are taken up by human cells but do not cause acute cytotoxicity. Small 1(3):325-327. https://doi. org/10.1002/smll.200400093

16. Correard F, Maximova K, Estève MA, Villard C, Roy M, Al-Kattan A, Braguer D (2014) Gold nanoparticles prepared by laser ablation in aqueous biocompatible solutions: assessment of safety and biological identity for nanomedicine applications. Int J Nanomed 9:5415-5430. https://doi.org/10.2147/IJN.S65817

17. De Souza CD, Nogueira BR, Rostelato MECM (2019) Review of the methodologies used in the synthesis gold nanoparticles by chemical reduction. J Alloys Compd 798:714-740. https://doi. org/10.1016/j.jallcom.2019.05.153

18. Dykman L, Khlebtsov N (2012) Gold nanoparticles in biomedical applications: recent advances and perspectives. Chem Soc Rev 41:2256-2282. https://doi.org/10.1039/C1CS15166E

19. Dzimitrowicz A, Jamróz P, diCenzo GC, Sergiel I, Kozlecki T, Pohl $P$ (2016) Preparation and characterization of gold nanoparticles prepared with aqueous extracts of Lamiaceae plants and the effect of follow-up treatment with atmospheric pressure glow microdischarge. Arab J Chem. https://doi.org/10.1016/j.arabj c.2016.04.004

20. Elahi N, Kamali M, Baghersad MH (2018) Recent biomedical applications of gold nanoparticles: a review. Talanta 184:537556. https://doi.org/10.1016/j.talanta.2018.02.088

21. Horikoshi S, Serpone N (2017) In-liquid plasma: a novel tool in the fabrication of nanomaterials and in the treatment of wastewaters. RSC Adv 7:47196-47218. https://doi.org/10.1039/C7RA0 $9600 \mathrm{C}$

22. Itoh H, Naka K, Chujo Y (2004) Synthesis of gold nanoparticles modified with ionic liquid based on the imidazolium cation. J Am Chem Soc 126(10):3026-3027. https://doi.org/10.1021/ ja039895g

23. Jameel ZN (2017) Synthesis of the gold nanoparticles with novel shape via chemical process and evaluating the structural, morphological and optical properties. Energy Procedia 119:236-241. https://doi.org/10.1016/j.egypro.2017.07.075

24. Kim EY, Kumar D, Khang G, Lim D (2015) Recent advances in gold nanoparticle-based bioengineering applications. J Mater Chem B 3:8433. https://doi.org/10.1039/C5TB01292A

25. Kim DS, Hwang NM (2018) Synthesis of nanostructures using charged nanoparticles spontaneously generated in the gas phase during chemical vapor deposition. J Phys D Appl Phys. https://doi.org/10.1088/1361-6463/aae4b7

26. Kumar D, Mutreja I, Sykes P (2016) Seed mediated synthesis of highly mono-dispersed gold nanoparticles in the presence of hydroquinone. Nanotechnology 27:355601. https://doi. org/10.1088/0957-4484/27/35/355601
27. Kunoh T, Takeda M, Matsumoto S, Suzuki I, Takano M, Kunoh H, Takada J (2018) Green synthesis of gold nanoparticles coupled with nucleic acid oxidation. ACS Sustain Chem Eng 6(1):364373. https://doi.org/10.1021/acssuschemeng.7b02610

28. Lee JH, Choi SUS, Jang SP, Lee SY (2012) Production of aqueous spherical gold nanoparticles using conventional ultrasonic bath. Nanoscale Res Lett 7:420. https://doi. org/10.1186/1556-276X-7-420

29. Li Z, Gu A (2009) Growth of spindle-shaped gold nanoparticles in cetyltrimethylammonium bromide solutions. Micro Nano Lett 4(3):142-147. https://doi.org/10.1049/mnl.2009.0047

30. Locke BR, Thagard SM (2012) Analysis and review of chemical reactions and transport processes in pulsed electrical discharge plasma formed directly in liquid water. Plasma Chem Plasma Process 32:875. https://doi.org/10.1007/s11090-012-9403-y

31. LaLonde AD, Norton MG, Zhang D, Gangadean D (2005) Controlled growth of gold nanoparticles on silica nanowires. J Mater Res 20(11):3021-3027. https://doi.org/10.1557/JMR.2005.0368

32. Lung J-K, Huang J-C, Tien D-C, Liao C-Y, Tseng K-H, Tsung T-T, Kao W-S, Tsai T-H, Jwo C-S, Lin H-M, Stobinski L (2007) Preparation of gold nanoparticles, by arc discharge in water. J Alloys Compd 434-435:655-658. https://doi.org/10.1016/j.jallcom.2006.08.213

33. Ma M, Zhang Y, Yu W, Shen H, Zhang H, Gu N (2003) Preparation and characterization of magnetite nanoparticles coated by amino silane. Colloids Surf A Physicochem Eng Asp 212(23):219-226. https://doi.org/10.1016/S0927-7757(02)00305-9

34. Mohamed MM, Fouad SA, Elshoky HA, Mohammed GM, Salaheldin TA (2017) Antibacterial effect of gold nanoparticles against Corynebacterium pseudotuberculosis. Int J Vet Sci Med 5(1):2329. https://doi.org/10.1016/j.ijvsm.2017.02.003

35. Mortazavi SM, Khatami M, Sharifi I et al (2017) Bacterial biosynthesis of gold nanoparticles using Salmonella enterica subsp. enterica serovar typhi isolated from blood and stool specimens of patients. J Clust Sci 28:2997. https://doi.org/10.1007/s1087 6-017-1267-0

36. Murphy CJ, Thompson LB, Chernak DJ, Yang JA, Sivapalan ST, Boulos SP, Huang J, Alkilany MA, Sisco PN (2011) Gold nanorod crystal growth: from seed-mediated synthesis to nanoscale sculpting. Curr Opin Colloid Interface Sci 16(2):128-134. https ://doi.org/10.1016/j.cocis.2011.01.001

37. Omurzak E, Jasnakunov J, Mairykova N, Abdykerimova A, Maatkasymova $A$, Sulaimankulov $S$, Matsuda $M$, Nishida $M$, Ihara $H$, Mashimo T (2007) Synthesis method of nanomaterials by pulsed plasma in liquid. J Nanosci Nanotechnol 7(9):3157-3159. https ://doi.org/10.1166/jnn.2007.804

38. Omurzak E, Abdullaeva $Z$, Iwamoto $C$, Ihara $H$, Sulaimankulova S, Mashimo T (2015) Synthesis of hollow carbon nano-onions using the pulsed plasma in liquid. J Nanosci Nanotechnol 15(5):3703-3709. https://doi.org/10.1166/jnn.2015.9278

39. Parab HJ, Chen HM, Lai T-C, Huang JH, Chen PH, Liu R-S, Hsiao M, Chen C-H, Tsai D-P, Hwu Y-K (2009) Biosensing, cytotoxicity, and cellular uptake studies of surface-modified gold nanorods. J Phys Chem C 113(18):7574-7578. https://doi.org/10.1021/jp900 0169

40. Rad AG, Abbasi H, Afzali MH (2011) Gold nanoparticles: synthesising, characterizing and reviewing novel application in recent years. Phys Procedia 22:203-208. https://doi.org/10.1016/j. phpro.2011.11.032

41. Semyannikov PP, Moroz BL, Trubin SV et al (2006) Chemical vapor infiltration method for deposition of gold nanoparticles on porous alumina supports. J Struct Chem 47:458. https://doi. org/10.1007/s10947-006-0323-7

42. Sheikhloo Z, Salouti M, Katiraee F (2011) Biological synthesis of gold nanoparticles by fungus Epicoccum nigrum. J Clust Sci 22:661. https://doi.org/10.1007/s10876-011-0412-4 
43. Singh AK, Srivastava ON (2015) One-step green synthesis of gold nanoparticles using black cardamom and effect of $\mathrm{pH}$ on its synthesis. Nanoscale Res Lett 10:353. https://doi.org/10.1186/s1167 1-015-1055-4

44. Sashuk V, Rogaczewski K (2016) A halogen-free synthesis of gold nanoparticles using gold(III)oxide. J Nanopart Res 18(9):261. https://doi.org/10.1007/s11051-016-3576-x

45. Sulaimankulova SK, Asanov UA (2002) Energy-saturated media in a spark discharge plasma. Kyrgyzpatent, Bishkek

46. Takagi D, Kobayashi Y, Hibino H, Suzuki S, Homma Y (2008) Mechanism of gold-catalyzed carbon material growth. Nano Lett 8(3):832-835. https://doi.org/10.1021/nl0728930

47. Wandell R, Hsieh K, Locke BR, Bresch S, Alabugin I (2013) Chemical reactions in pulsed plasma with organic liquid spray. In: 2013 abstracts IEEE international conference on plasma science (ICOPS), San Francisco, CA, pp 1-1. https://doi.org/10.1109/ PLASMA.2013.6634891

48. Wender H, Andreazza ML, Correia RRB, Teixeira SR, Dupont J (2011) Synthesis of gold nanoparticles by laser ablation of an
Au foil inside and outside ionic liquids. Nanoscale 3:1240-1245. https://doi.org/10.1039/CONR00786B

49. Xie X, Liao J, Shao X, Li Q, Lin Y (2017) The effect of shape on cellular uptake of gold nanoparticles in the forms of stars, rods, and triangles. Sci Rep 7:3827. https://doi.org/10.1038/s4159 8-017-04229-z

50. Yeh YC, Creran B, Rotello VM (2011) Gold nanoparticles: preparation, properties, and applications in bionanotechnology. Nanoscale 4(6):1871-1880. https://doi.org/10.1039/C1NR1 $1188 \mathrm{D}$

51. Zhu N, Ji H, Yu P, Niu J, Farooq MU, Akram MW, Udego IO, Li H, Niu X (2018) Surface modification of magnetic iron oxide nanoparticles. Nanomaterials 8:810. https://doi.org/10.3390/nano8 100810

Publisher's Note Springer Nature remains neutral with regard to jurisdictional claims in published maps and institutional affiliations. 